\title{
TOOLS TO ENGAGE YOUTH IN ENVIRONMENTAL ISSUES DURING COVID-19 PANDEMIC: CONSTANTA MARITIME UNIVERSITY APPROACH
}

\author{
Mirela-Iuliana Sundri ${ }^{1}$ \& Feiza Memet ${ }^{1}$ \\ ${ }^{1}$ Constanta Maritime University, Faculty of Naval Electro-Mechanics, 104 Mircea cel Batran Street, 900663 , \\ Constanta, Romania, e-mail address: iuliana.sundri@cmu-edu.eu
}

\begin{abstract}
Environmental sustainability must be considered as the main target of humanity. To achieve this goal, the activities of many people must change into pro-environmental behaviour. This is often difficult because it involves high costs, giving up some daily habits and getting out of an artificial comfort. In this sense, education has an essential role to play. Young people are the target group for which appropriate methods must be found to help raise awareness of environmental issues and their involvement in solving them. In the current situation, under the restrictions caused by the Covid-19 pandemic, practical applications with large groups of students and observation of the wild environment is difficult to achieve. In November 2020, the Department of Mechanical and Environmental Sciences within the Maritime University of Constanta organized online the activity "S.O.S. Nature" where different environmental processes have been highlighted through simulation programs. The event aimed to increase the awareness of young people about environmental pollution and its consequences, as well as stimulating transversal skills by high school students participating. The interest given by the large participation in this event and the knowledge gained in this activity underlined the importance of modelling and simulation as useful tools through whose comprehensive approach young people can understand complex environmental issues.
\end{abstract}

Key words: environment, integrated approach, pandemic, pro-environmental behaviour, simulation.

\section{INTRODUCTION}

Global environmental changes represent one of the main problems confronting the international community. Environmental sustainability is perhaps the main goal that humanity must consider. Although there has been and is much discussion about the steps that need to be taken at different levels to achieve this goal, there are still many people who do not realize the need to change our behaviour towards actions on nature. Given the complexity of environmental processes, many categories of people ignore imbalances in natural ecosystems because they cannot link cause and effect. In this sense, education has an essential role in promoting proenvironmental behaviour among the broad masses of people and especially among young people. To this end, it is essential to choose the best methods and tools to raise awareness of environmental issues and motivate young people to approach appropriate behaviour [1].

In the local community, Constanta Maritime University it is also recognized as a promotor of environmental awareness among youth. Because of the vulnerability resulted from COVID-19 pandemic reality, the university had to reconsider its environmental awareness actions. Thus, face to face activities were shifted to online activities. This paper describes how technology can be used in order to provide knowledge in social distancing conditions, with optimum results.

\section{PRO-ENVIRONMENTAL BEHAVIOUR}

At the beginning of this millennium we are accustomed to a way of life that we consider comfortable, although with sometimes serious consequences for our health. Locked up in overcrowded cities, we have moved away from nature and we are no longer able to see that nature is suffering. Air, soil or water pollution has the effect of reducing biodiversity and climate change. Environmental problems affect the entire planet, and scientists warn of the worsening of negative effects if radical action is not taken.

However, the measures to be implemented are not always well received by the people. These measures imply a shift in our behaviour toward a proenvironmental behaviour that involves a change in our daily habits [2] [3] [4]; we must try to give up cars and walk more, not to waste water, food, clothes, household items; take care where we store waste. To apply all these measures, we need to feel nature, stay longer in nature and understand nature.

Taking into account the age groups in the population structure, young people are the ones who will 
suffer in the long run following wrong decisions regarding the good management of environmental problems. That is why they should be militant and have pro-environmental behaviour [5]. Unfortunately, many of the young people have moved away from nature, some of them have not left the overcrowded cities for years. They cannot understand environmental issues and do not accept environmental protection measures because they do not have a comparative factor. Many high school students spend much of their time playing various computer games. They do not feel nature. For some of them it is difficult to give up the permanent purchase of clothes and accessories, the return of the old traditional material or the abandonment of disposable packaging.

Engaging youth in solving environmental problems is an important issue for every nation. In order for young people to be aware of the serious environmental problems at global level and to change their behaviour towards sustainability, an important role belongs to the education process [6].

However, young people are very receptive to the new [7]. Given this character trait, they are the part of the population we can focus on first and foremost in a modern approach to environmental issues.

\section{INTEGRATED APPROACH OF ENVIRONMENTAL PROBLEMS}

Environmental processes are complex and difficult to understand, especially for those unfamiliar with this field. To understand them you need in-depth knowledge of chemistry, biology, physics, mathematics, meteorology, etc. In this sense, the models developed and used in various simulation programs that provide an integrated approach to environmental issues and provide an overview of the processes in nature, using data provided from different fields, are of real use. The interdisciplinary and multidisciplinary approach to environmental issues highlights the risks associated with different activities and helps to make the right decisions quickly. With the help of simulations, short or long term forecasts associated with the impact of human activities can be made and in this way the necessary corrections can be highlighted.

Involving youth in environmental issues is a goal for all countries and from this perspective modeling and simulation are extremely useful tools. Simulation programs are modern methods, with which a variety of data can be accessed and countless scenarios can be created. Young people understand natural phenomena through work tools they love, being accustomed to computer games.

\section{CONNECTING YOUNG PEOPLE TO ENVIRONMENTAL ISSUES DURING THE COVID-19 PANDEMIC}

The restrictions imposed by the Covid-19 pandemic and the online educational process have further highlighted the usefulness of models and simulation processes.

On November 27, 2020, the Department of Engineering Sciences in the Mechanical Field and Environment from Constanta Maritime University organized online the activity "S.O.S. Nature". In this activity, with the help of simulation programs, different environmental processes were highlighted. The event aimed to increase the awareness of young people about environmental pollution and its consequences, as well as stimulating transversal skills of high school final classes students.

The event was attended by 61 students from 9 high schools in Constanta and Tulcea counties. The students were assisted online by students of the study program Engineering and Environmental Protection in Industry.

During the "S.O.S. Nature" activity, students were introduced to the HYSPLIT and FoodWeb simulation programs, both of the freeware type, easily accessible by users, from a PC or smartphone, both software with a user-friendly graphical interfaces. The students worked simultaneously with the teacher's demonstration, they became familiar with how to install and run these programs, as well as with the interpretation of the results obtained from these simulations.

HYSPLIT was developed by the US National Oceanic and Atmospheric Administration [8]. This is a model for calculating the dispersion of substances in the atmosphere as well as their deposition. The students simulated a particle pollution. Students became aware of the importance of weather conditions for the speed and movement of pollutant, for atmospheric concentrations of particles (see figures 1 and 2.) and their deposition on the ground (see figure 3). Graphical results in $\mathrm{KMZ}$ format that displays data in the Google Earth browser (see figure 4) or in .gif format, or were very suggestive. 


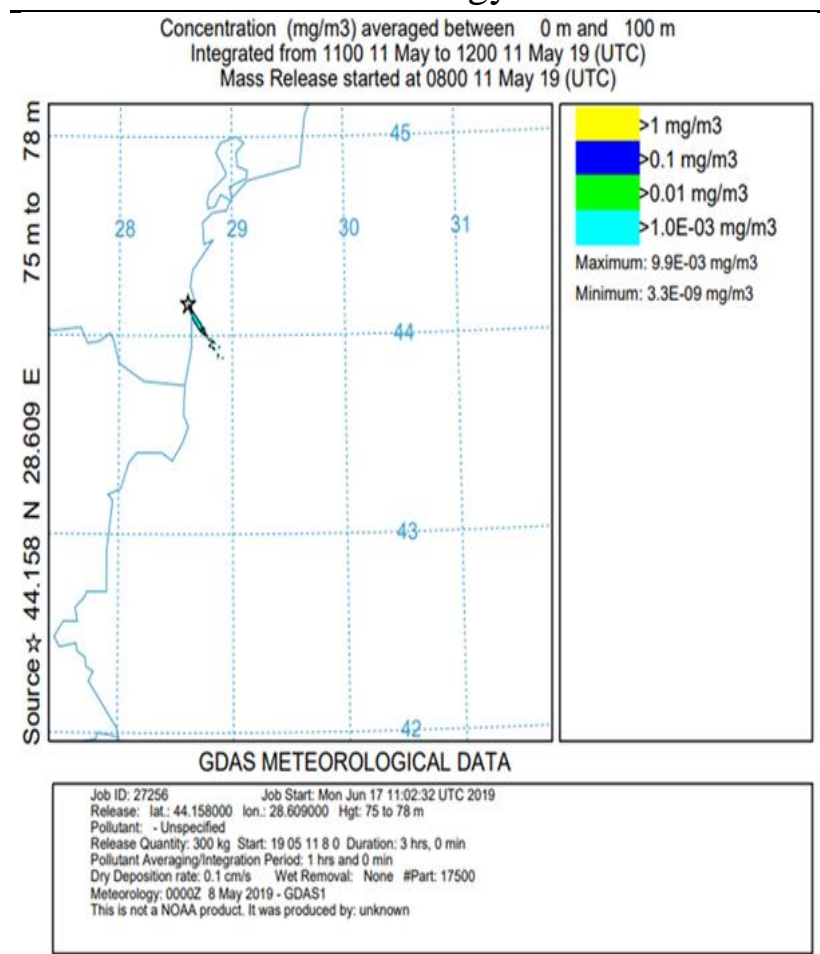

Figure 1. Particle dispersion in the atmosphere - results of the HYSPLIT simulation

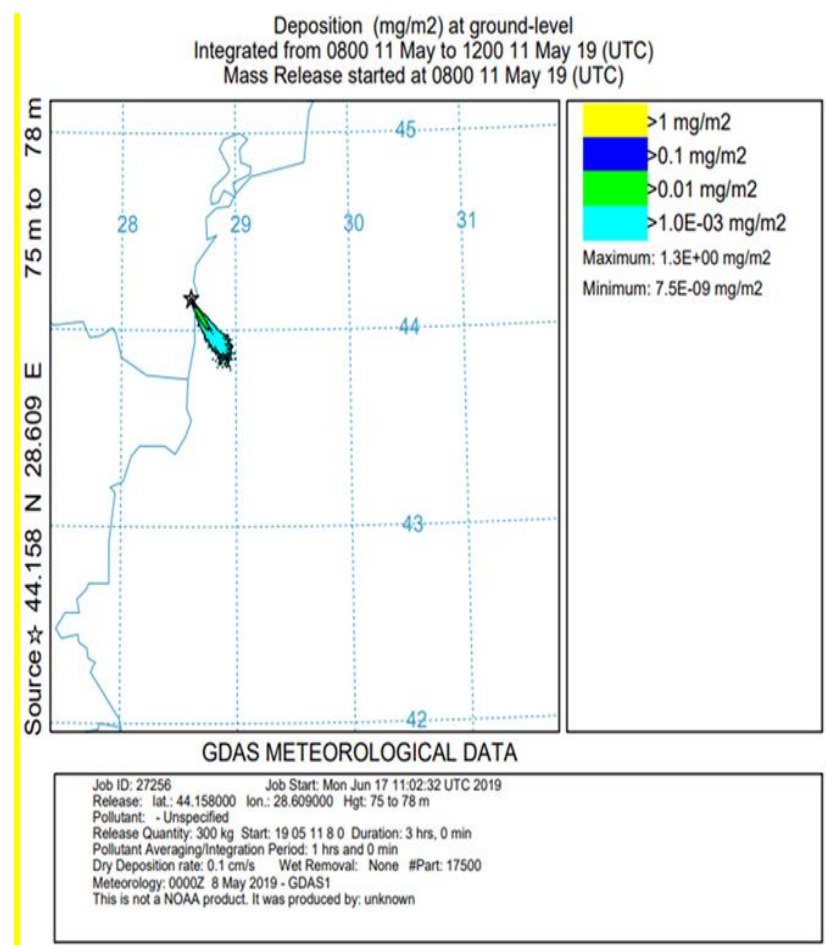

Figure 2. Particle deposition at soil level - results of the HYSPLIT simulation

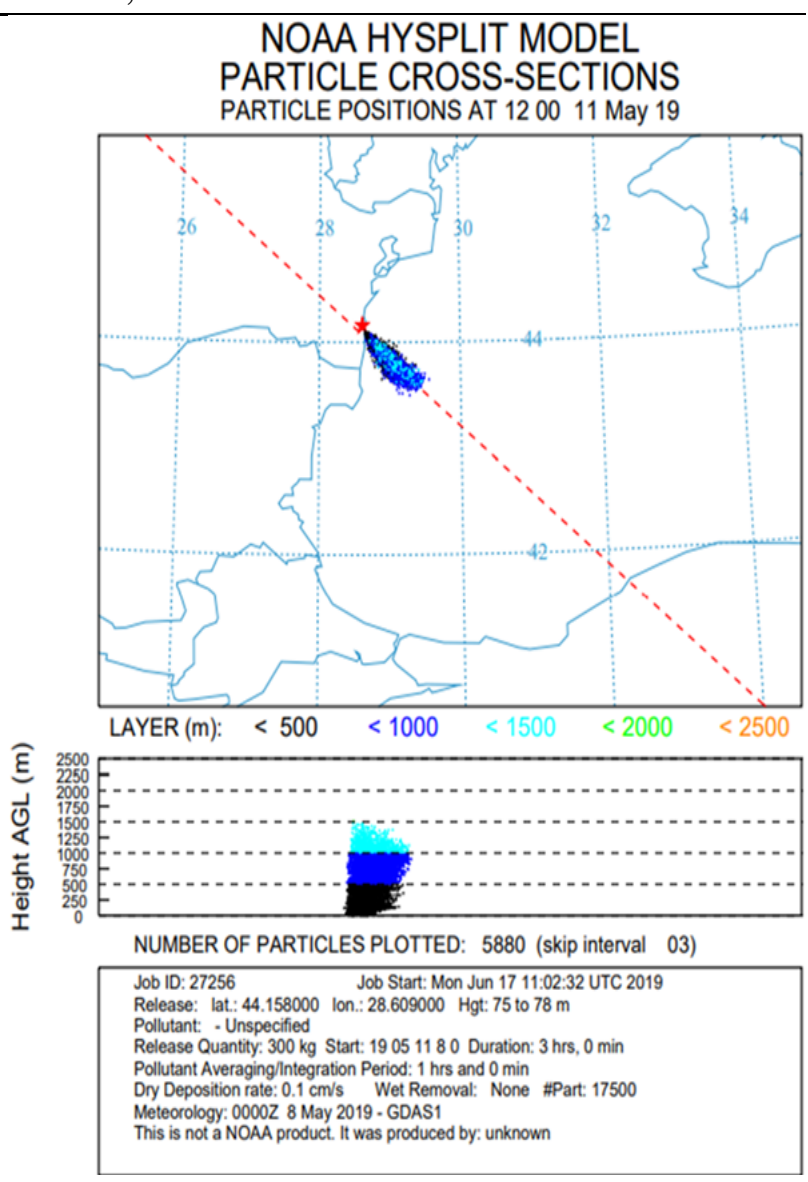

Figure 3. Particle cross-section - results of the HYSPLIT simulation

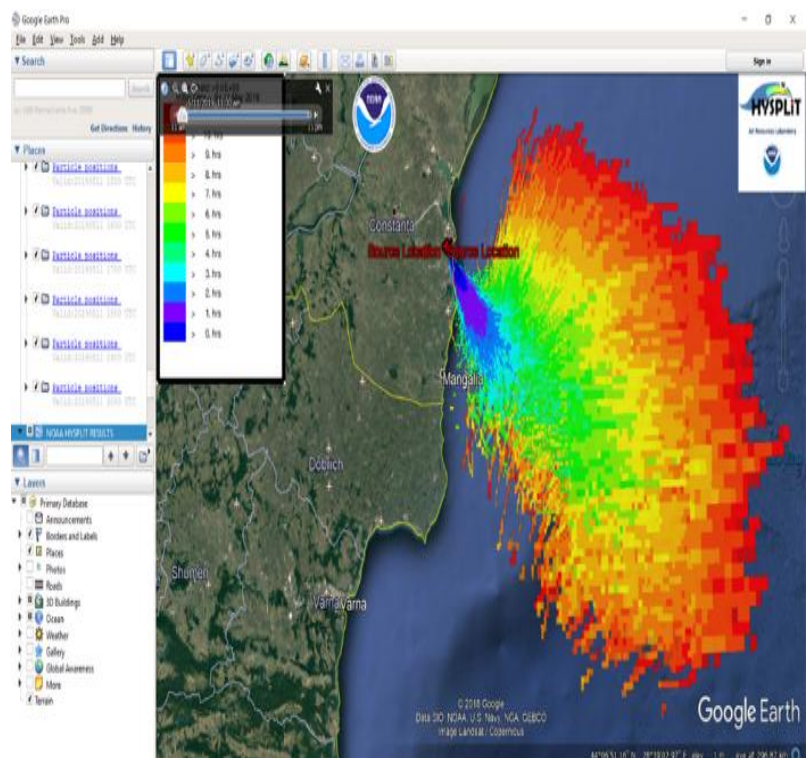

Figure 4. Graphical results of the exercise in the Google Earth browser

The second model used, FoodWeb, was developed by the Canadian Environmental Modelling Center from 
Journal of Marine technology and Environment Year 2021, Vol.I

Trent University [9]. It is a model of bioaccumulation in complex aquatic systems. With its help, students had the opportunity to track the fate of pollutants along the food chain, to understand that the effects of pollution depend on the type of toxic substance, the abiotic characteristics and the biodiversity of the ecosystem. According to data found in the scientific literature, students designed an aquatic ecosystem with abiotic (see figure 5) and biotic (see figure 6) characteristics, simulating its pollution. Through the simulation program, students received information about the routes of uptake and elimination of a pollutant and highlighted the specific bioaccumulation of the toxicant in various organisms (see figure 7 and figure 8). Students became aware of the importance of simulations to predict the long-term effects of various human activities.

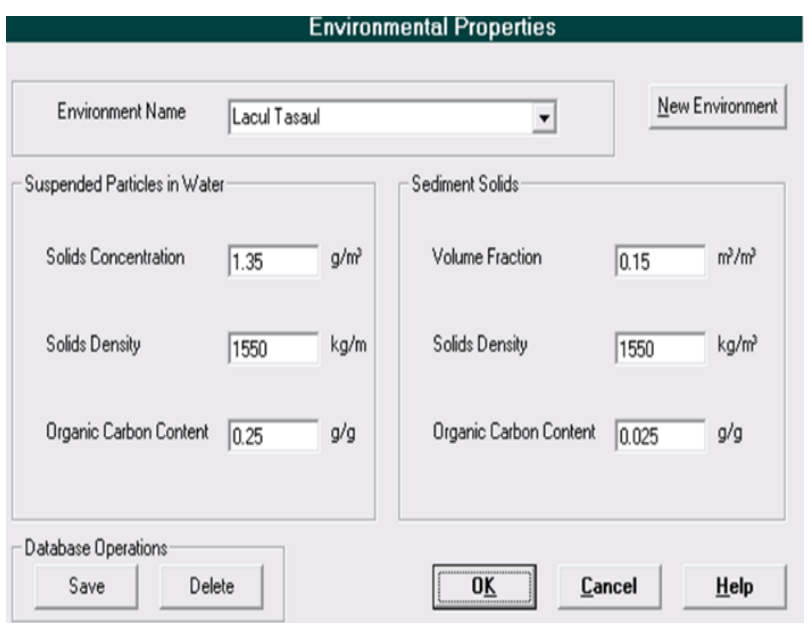

Figure 5. Aquatic environment specific properties

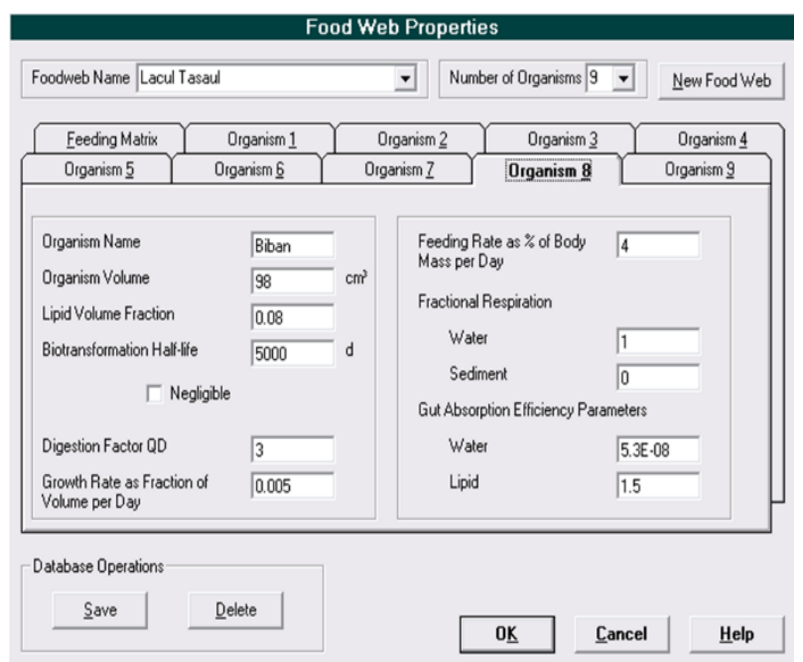

Figure 6. Aquatic Food Web properties

\begin{tabular}{|c|c|c|}
\hline FoodWeb Model & Chemical Name & Beno/g/olome \\
\hline \multirow[t]{2}{*}{ Vestion 200} & Environment Name & LaculTasoul \\
\hline & Foodweb Name & LaCul TasaUl \\
\hline
\end{tabular}

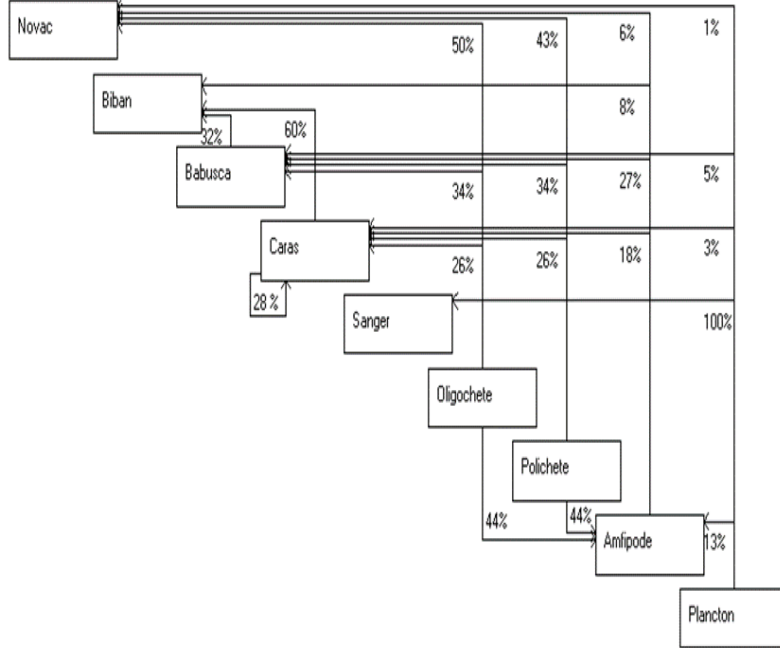

Figure 7. Aquatic specific Food Web Model

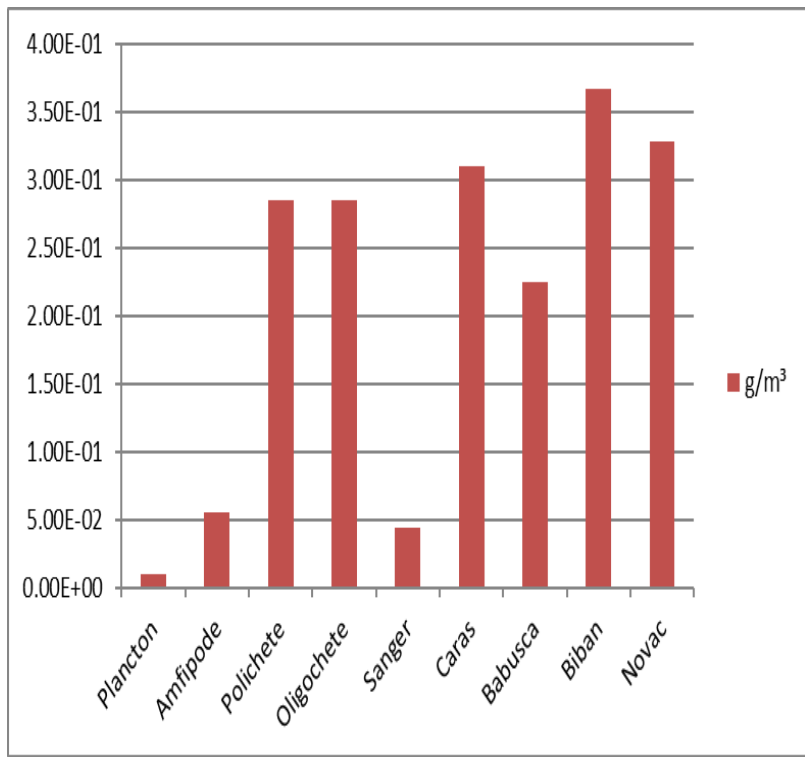

Figure 8. Toxicant bioaccumulation in the food chain

The activity ended with a competition through which the level of accumulation of acquired knowledge was tested. 83 percent of participants answered all the questions correctly. The results obtained demonstrated the interest of young people to understand pollution phenomena and to find ways to solve environmental problems.

\section{CONCLUSIONS}

At international level, environmental education is affected by the pandemic restrictions. Higher education 
approach and transfer its attention on the online educational mode, in order to be able to continue its environmental activity with the young people.

Within "S.O.S. Nature" activity, to the students were provided data and exercises to practice interpreting environmental processes. In this way they were able to draw their own conclusions. This increase in awareness of the phenomena that occur around them determines a major involvement in achieving environmental goals by addressing pro-environmental behaviour.

\section{REFERENCES}

[1] Gianluca Grilliab, John Curtisa, 2021, Encouraging pro-environmental behaviours: A review of methods and approaches, Renewable and Sustainable Energy Reviews, Volume 135, January 2021, 110039

[2] Heather Barnes Truelovea Ashley Jade Gillisb, 2018, Perception of pro-environmental behavior, Global Environmental Change, Volume 49, March 2018, Pages 175-185

[3] Florian Lange, Siegfried Dewitte, 2019, Measuring pro-environmental behavior:

Review and recommendations, Journal of Environmental Psychology, Volume 63, June 2019, Pages 92-100

[4] Audra Balunde, Goda Perlaviciute, Linda Steg, 2019, The Relationship Between People's Environmental Considerations and Pro-environmental Behavior in Lithuania, Front. Psychol., 15 October 2019.

[5] Heejin Han, Sang Wuk Ahn, 2020, Youth Mobilization to Stop Global Climate Change: Narratives and Impact, MDPI, Sustainability 2020, 12, 4127; doi:10.3390/su12104127.

[6] [Daniel Thor, Peter Karlsudd, 2020, Teaching and Fostering an Active Environmental Awareness Design, Validation and Planning for Action-Oriented Environmental Education, MDPI, Sustainability 2020, 12, 3209; doi:10.3390/su12083209

[7] Najla Mouchrek, 2018, Engaging College Students in the Transition to Sustainability Through Design-Based Approaches, The Journal of Sustainable Development, Vol. 20, Iss. 1, Pp. 88-103.

[8] https://www.ready.noaa.gov/HYSPLIT.php

[9] https://tuspace.ca/ mparnis/files/Foodweb200.html 